\title{
Cerebral and Adrenal Monoamine Metabolism in the Growth-Retarded Rat Fetus under Normoxia and Hypoxia
}

\author{
MAGNUS THORDSTEIN AND THOMAS HEDNER \\ Departments of Physiology and Pediatrics I [M.T.], Pharmacology and Clinical Pharmacology [T.H.], \\ University of Göteborg, Göteborg, Sweden
}

\begin{abstract}
The effect of intrauterine growth retardation (IUGR) on cerebral and adrenal monoamine metabolism was studied in the fetuses of eight nulliparous rat dams after unilateral uterine artery ligation on $\mathbf{d} 18$ of gestation. On d 22 (term $=23 \mathrm{~d}$ ), four dams were subjected to normoxia and four to hypoxia $\left(10 \% \mathrm{O}_{2}\right)$ for 58 min while their hemodynamics and blood gases were monitored. An inhibitor of $\mathrm{L}$-aromatic-decarboxylase (3-hydroxybensylhydrazine) was infused to measure monoamine synthesis rate. After decapitation of the dam, fetuses were delivered by sectio, decapitated, and dissected at $-5^{\circ} \mathrm{C}$. The body, liver, forebrain, brainstem, and adrenal glands were weighed, and concentrations of monoamine precursors, transmitters, and metabolites were assessed in the three latter organs. The weights of liver and forebrain were reduced in fetuses with IUGR, whereas brainstem and adrenal weights were unaltered. Epinephrine content in adrenals was reduced in proportion to body weight under normoxia but failed to increase under hypoxia as it did in appropriately grown fetuses. There were only minor changes in monoamine metabolism in the brainstem. In the forebrain, however, marked changes were seen, mainly in serotonin metabolism: under normoxia, fetuses with IUGR had decreased levels of serotonin and its metabolite 5hydroxyindole acetic acid. Under hypoxia, appropriately grown fetuses reduced their concentrations of these substances, whereas fetuses with IUGR paradoxically increased their synthetic activity. It is concluded that a disturbance of central nervous serotonin metabolism prevails in growth-retarded rat fetuses in late gestation and that this disturbance depends on the degree of growth retardation and the degree of perinatal stress. (Pediatr Res 31: 131-137, 1992)
\end{abstract}

\section{Abbreviations}

MA, monoamine

CA, catecholamine

DOPA, dihydroxyphenylalanine

DA, dopamine

DOPAC, 3,4-dihydroxyphenylacetic acid

NE, norepinephrine

E, epinephrine

5-HTP, 5-hydroxytryptophan

Received October 5, 1990; accepted August 1, 1991.

Correspondence: M. Thordstein, Div. Perinatal Physiology, Dept. Physiology, University of Göteborg, P.O. Box 33031, S-400 33 Göteborg, Sweden.

Supported by the Swedish Medical Research Council (Grants No. 2591, 8642 and 2855), the General Maternity Hospital Foundation, the Magnus Bergval Foundation, the Faculty of Medicine, University of Göteborg, the Göteborg Medical Society, the "Samariten" Foundation, the Sahlgrenska Hospital Foundation, the "Sven Jerring" Foundation, the Swedish Medical Society, and the Expressen Prenatal Research Foundation.

\author{
5-HT, 5-hydroxytryptamine \\ 5-HIAA, 5-hydroxyindole acetic acid \\ MAP, mean arterial pressure \\ HR, heart rate \\ NSD 1015, 3-hydroxybensylhydrazine \\ IUGR, intrauterine growth retardation \\ AGA, appropriately grown for gestational age
}

Fetuses and neonates who are small for gestational age because of IUGR are at increased risk to develop both minor $(1,2)$ and major $(3,4)$ neurodevelopmental sequelae. This could be due to an increased risk of asphyxia (5) or an increased sensitivity of the CNS in growth-retarded individuals (6). Indications of an altered central nervous function have been found in growthretarded human fetuses [motor function $(7,8)$ and cardiovascular regulation (9)] and neonates [evoked potentials (10)]. In growthretarded compared to AGA animal fetuses, changes of cerebral circulation (11) and evoked potentials (12) have been shown. Moreover, modifications of evoked potentials (6) and MA metabolism (13) are present in newborn growth-retarded animals when compared with AGA animals.

Besides their role as neurotransmitters, MA have trophic effects on cerebral development (14), and manipulations of these systems perinatally have longstanding effects on cerebral function (15) and behavior $(16,17)$. These transmitters, i.e. DA, NE, and 5-HT, have also been implied in the pathophysiology of brain damage from various kinds of stress $(18-20)$. The growth-retarded fetus often suffers from a mild hypoxia (21) and an insufficient supply of essential amino acids (22), which could influence the synthesis of the MA neurotransmitters $(23,24)$.

The aim of the present study was to investigate, in a model with late placental insufficiency relevant to the human situation (25), the effect of IUGR on cerebral and adrenal MA metabolism in the rat fetus under basal (maternal normoxia) and stressful (maternal hypoxia) conditions. This could make it possible to judge if a disturbed MA metabolism could be part of the pathophysiology resulting in an increased risk of neurodevelopmental handicaps in individuals with IUGR.

\section{MATERIALS AND METHODS}

Animal handling. Sprague-Dawley male and female rats (ALAB, Stockholm, Sweden) were housed separately with food (standard pellets) and water ad libitum under stable environmental conditions: 12-h light-darkness cycles (switched at 0600 and $1800 \mathrm{~h}$ ), humidity $55 \%$, and temperature $22^{\circ} \mathrm{C}$. Mating was allowed for $24 \mathrm{~h} \mathrm{(d} \mathrm{0).} \mathrm{Eight} \mathrm{nulliparous} \mathrm{pregnant} \mathrm{females} \mathrm{were}$ kept in separate cages from d 14 of pregnancy (term $=23 \mathrm{~d}$ ) until d 18, when unilateral uterine artery ligation was performed. 


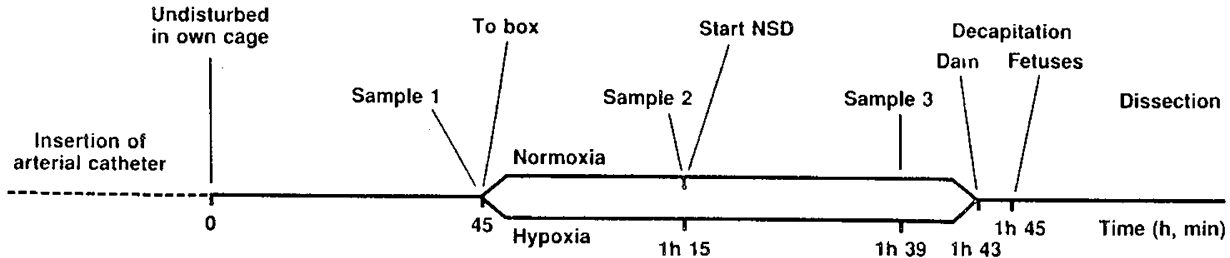

Fig. 1. Experimental protocol.

Table 1. MAP, HR, oxygen content $\left(\mathrm{O}_{2}\right.$-ct), partial pressure of oxygen $\left(\mathrm{PaO}_{2}\right), \mathrm{pH}$, and $\mathrm{NE}$ and $E$ concentrations for two groups of

\begin{tabular}{|c|c|c|c|c|c|c|c|}
\hline & $\begin{array}{c}\text { MAP } \\
(\mathrm{mm} \mathrm{Hg})\end{array}$ & $\begin{array}{c}\text { HR } \\
(\mathrm{bpm})\end{array}$ & $\begin{array}{c}\mathrm{O}_{2} \text {-ct } \\
(\mathrm{mmol} / \mathrm{L})\end{array}$ & $\begin{array}{l}\mathrm{PaO}_{2} \\
(\mathrm{kPa}) \\
\end{array}$ & $\mathrm{pH}$ & $\begin{array}{c}\mathrm{NE} \\
(\mathrm{ng} / \mathrm{mL})\end{array}$ & $\begin{array}{c}E \\
(\mathrm{ng} / \mathrm{mL})\end{array}$ \\
\hline \multicolumn{8}{|l|}{ Sample 1} \\
\hline \multirow[t]{2}{*}{ Normoxia } & 96 & 398 & 6.9 & 14.32 & 7.42 & 1.42 & 0.91 \\
\hline & 3 & 11 & 0.2 & 0.72 & 0.01 & 0.31 & 0.50 \\
\hline \multirow[t]{2}{*}{ Hypoxia } & 100 & 422 & 6.8 & 12.94 & 7.44 & 1.37 & 0.54 \\
\hline & 5 & 29 & 0.2 & 0.51 & 0.01 & 0.29 & 0.19 \\
\hline \multicolumn{8}{|l|}{ Sample 2} \\
\hline \multirow[t]{2}{*}{ Normoxia } & 95 & 398 & 6.4 & 14.58 & 7.42 & & \\
\hline & 2 & 10 & 0.2 & $0.38 \dagger$ & $0.01 \dagger$ & & \\
\hline \multirow[t]{2}{*}{ Hypoxia } & 85 & 428 & 5.4 & 5.13 & 7.56 & & \\
\hline & 5 & 26 & 0.3 & $0.12 \dagger$ & $0.02 \dagger$ & & \\
\hline \multicolumn{8}{|l|}{ Sample 3} \\
\hline \multirow[t]{2}{*}{ Normoxia } & 90 & 375 & 6.5 & 12.32 & 7.34 & 1.94 & 10.13 \\
\hline & 4 & $34 \ddagger$ & $0.3 \neq$ & $0.84 \dagger$ & $0.03+$ & 0.63 & 0.85 \\
\hline \multirow[t]{2}{*}{ Hypoxia } & 88 & $461^{\circ}$ & $5.4^{\circ}$ & 5.58 & $7.45^{\circ}$ & 1.02 & 10.10 \\
\hline & 2 & $3 \neq$ & $0.3 \ddagger$ & $0.31 \dagger$ & $0.03 \ddagger$ & 0.15 & 0.95 \\
\hline
\end{tabular}

* Mean values are in the top row for each group; SEM are in the bottom row. $n=4$ in both groups.

$\uparrow$ Significant difference between groups: $p<0.001$.

$\$$ Significant difference between groups: $p<0.05$.
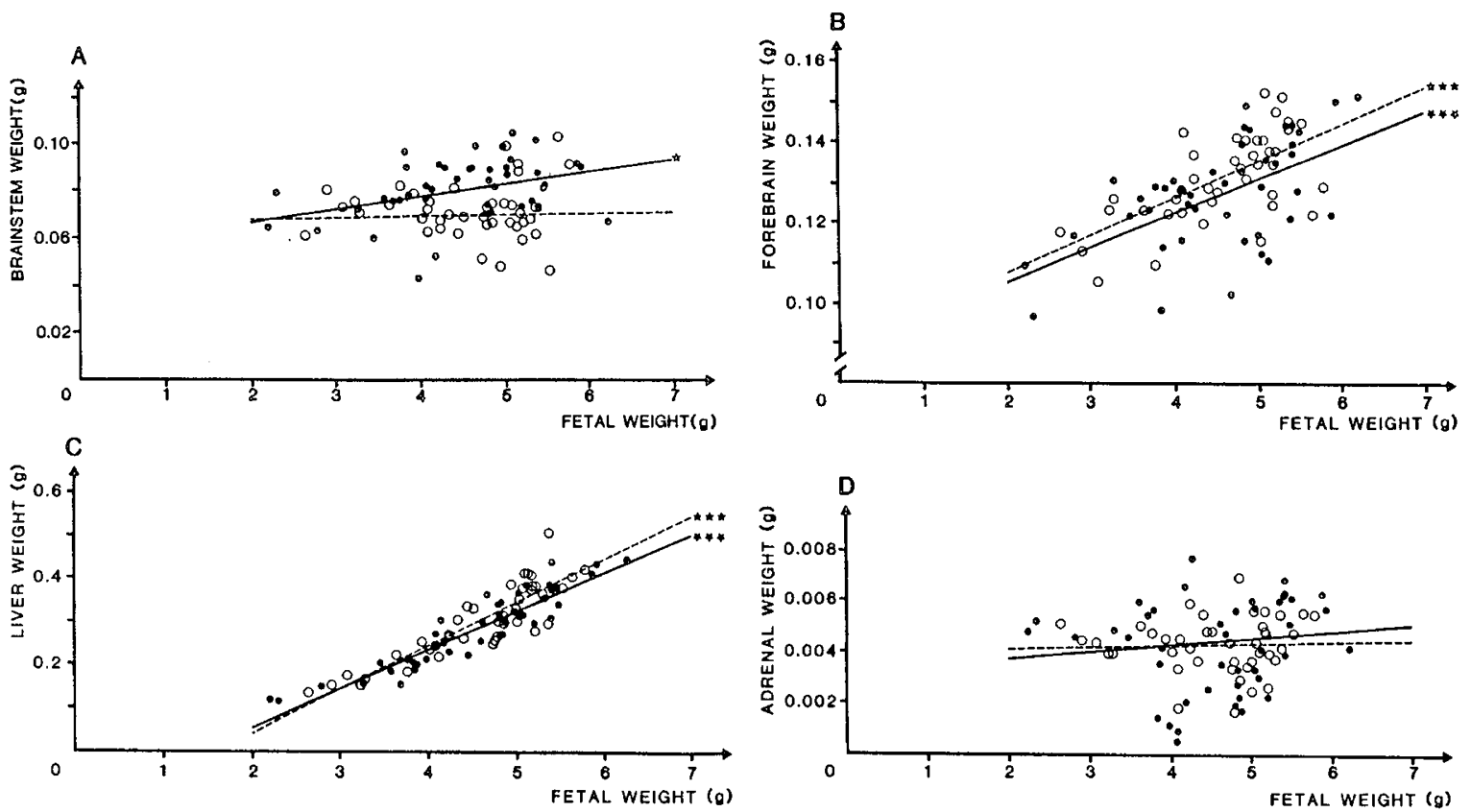

Fig. 2. Weights $(\mathrm{g})$ of brainstem $(A)$, forebrain $(B)$, liver $(C)$, and adrenals $(D)$. $A$, Normoxia: $y=0.067+0.001 x$; hypoxia: $y=0.058+0.005 x$. $B$, Normoxia: $y=0.090+0.009 x$; hypoxia: $y=0.089+0.008 x$. $C$, Normoxia: $y=-0.153+0.098 x$; hypoxia: $y=-0.126+0.090 x . D$, Normoxia: $y=0.004+0.0001 x$; hypoxia: $y=0.003+0.0003 x$. Individual values and regression lines are shown. (The regression equation was $\mathrm{Y}=\mathrm{a}+\mathrm{b} \cdot \mathrm{fetal}$ weight, where $\mathrm{Y}$ is the measured variable). Individual values are shown as open (normoxia) or filled (hypoxia) circles. The regression lines are indicated by broken (normoxia) or continuous (hypoxia) lines. A significant dependency of the measured variable on fetal weight is indicated by star(s) at the end of the line: $\star, p<0.05 ; \star \star, p<0.01$; and $\star \star \star, p<0.001$.

With the rats under enflurane anesthesia ( $3 \%$ for induction, $2 \%$ for maintenance, oxygen/nitrous oxide 1:1), a 2 -cm long lower midline incision was made and the uterine artery and vein were ligated. Time under anesthesia was 10-30 min, and the dams recovered within $3 \mathrm{~min}$. The surgical procedures were carried out between 1000 and $1200 \mathrm{~h}$.

Experimental procedures. On d 22 the experiment was performed between 0815 and $1300 \mathrm{~h}$ according to the outline in 

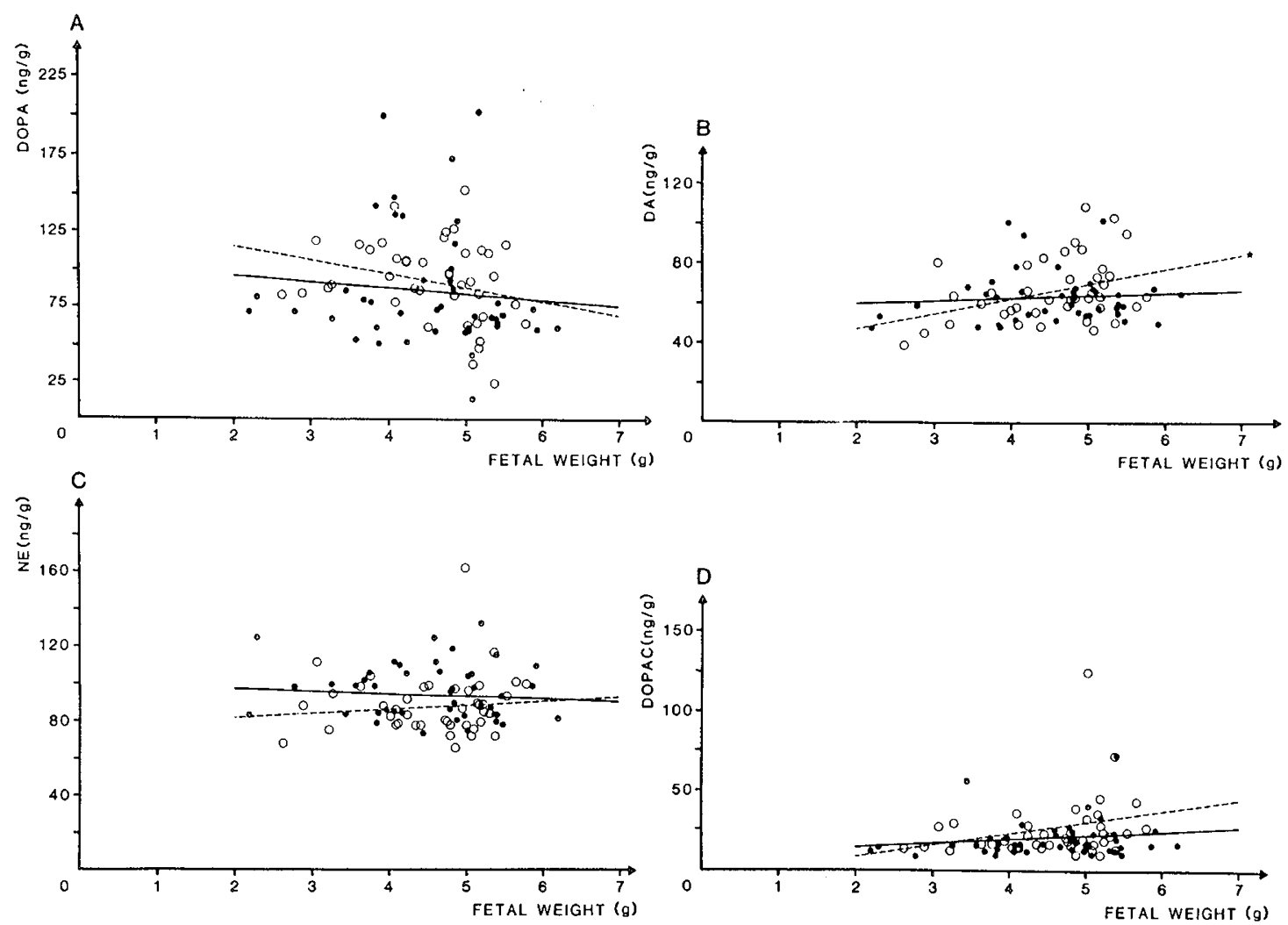

Fig. 3. Concentrations (ng/g) of CA precursor DOPA $(A)$, transmitters DA $(B)$ and NE $(C)$, and metabolite DOPAC $(D)$ in brainstem. $A$, Normoxia: $y=133.1-8.9 x$, hypoxia: $y=103.2-3.8 x$. B. Normoxia: $y=31.7+7.5 x$; hypoxia: $y=56.0+1.4 x$. C, Normoxia: $y=79.0+2.3 x$; hypoxia: $y=101.9-1.3 x$. $D$, Normoxia: $y=-4.7+6.7 x$; hypoxia: $y=10.1+2.2 x$. Lines and symbols are as indicated in Figure 2 .

Figure 1. A polyethylene catheter (PE 50, inner diameter 0.58 $\mathrm{mm}$ connected to PE 90 , inner diameter $0.86 \mathrm{~mm}$ ) was inserted in the tail artery with the dam under enflurane anesthesia (details as above). The dam was placed in her own cage in a separate room behind a screen and connected to a pressure transducer $(\mathrm{P}$ 23 ID Statham Gould, A; Gould Inc., Hato Rey, Puerto Rico) via a swivel that allowed her to move freely. MAP and HR (oscillation detector) were recorded continuously on a Grass polygraph No. 7 (Grass Instrument Co., Quincy, MA) outside the room.

After $45 \mathrm{~min}$, blood sampling was performed for determination of arterial blood gas status (ABL 30; Radiometer, Copenhagen, Denmark), Hb concentration, and oxygen saturation (OSM 2 Hemoximeter; Radiometer), as well as circulating CA levels. For these measurements (sample 1), 0.4 (blood gases and $\mathrm{Hb}$ ) and $0.6 \mathrm{~mL}(\mathrm{CA})$ of blood were taken.

Thereafter, the dam was moved to a Plexiglas box with either room air or $10 \%$ oxygen in nitrogen (on-line detection with Taylor Servomex OA 250; Taylor Servomex Ltd., Sussex, England) at a flow rate of $3 \mathrm{~L} / \mathrm{min}$ (sufficient to give unaltered oxygen concentration at the outflow of the box). Temperature in the box was kept at $22^{\circ} \mathrm{C}$ using a heating lamp. At $1 \mathrm{~h} 15 \mathrm{~min}$, sample $2(0.4 \mathrm{~mL}$ for determinations as above) was taken. Thereafter, NSD 1015 was administered. The dose was $10 \mathrm{mg} /$ $100 \mathrm{~g}$ body wt given as a slow infusion $(0.17 \mathrm{~mL} / \mathrm{min}, 20 \mathrm{mg}$ NSD $1015 / \mathrm{mL}$ ) (The NSD 1015 batch used was synthesized by H. Wikström at the Department of Pharmacology.) Sample 3 $(0.4$ and $0.6 \mathrm{~mL})$ was taken at $1 \mathrm{~h} 39 \mathrm{~min}$, followed by decapitation of the dam (1 h $43 \mathrm{~min}$ ) and fetuses ( $1 \mathrm{~h} 45 \mathrm{~min})$. There were nine to 15 fetuses per dam, totaling 46 and 43 in the normoxic and hypoxic groups, respectively. The fetuses were dissected on a plate cooled by dry ice $\left(-5^{\circ} \mathrm{C}\right)$. Forebrain (detached rostrally at the insertion of olfactorial tubercles and caudally along the caudal end of the hemispheres), brainstem (including cerebellum), liver, and adrenal glands were dissected out and weighed to the nearest $0.1 \mathrm{mg}$ (AND, ER 60-A; A\&L Company, Ltd., Tokyo, Japan). All organs but the liver were frozen on dry ice within $30 \mathrm{~min}$ and stored at $-70^{\circ} \mathrm{C}$ until biochemical analysis.

Samples for plasma CA determinations were kept on ice and the whole blood was mixed with $100 \mu \mathrm{L}$ saline solution $(0.09 \%$ $\mathrm{NaCl}$ with $9 \mathrm{mg}$ EGTA and $6 \mathrm{mg}$ glutathione), centrifuged immediately, and then frozen at $-70^{\circ} \mathrm{C}$

Analytical procedures. For MA analysis, the frozen samples were thawed and homogenized. After acid extraction, centrifugation, and filtration, the tissue levels of the precursor DOPA, DA, NE, E, and the metabolite DOPAC as well as the precursor 5-HTP, 5-HT, and the metabolite 5-HIAA were determined by HPLC with electrochemical detection. The HPLC-electrochemical methods were adapted from procedures previously described (26-28). Plasma CA were analyzed by HPLC as previously described (29).

Statistical analysis. In the normoxic group, four fetuses were excluded before statistical analysis was performed because of technical errors in the determination of cerebral MA. This group thus comprised 42 fetuses. Tests of significance were made using two-tailed $t$ test. A $p$ value $<0.05$ was considered significant. Maternal variables from the normoxic and hypoxic groups were compared. The dependencies of organ weights and concentrations of MA were analyzed using linear regression analysis with fetal weight as the independent variable. Significance of deviation of the slope from zero was tested. Moreover, the group values for AGA fetuses in the normoxic and hypoxic groups were compared. AGA fetuses were defined as having fetal weight greater than mean $-1 \mathrm{SD}$. The limit for normal growth $(4.78 \mathrm{~g})$ was determined from 79 fetuses in unligated horns in 13 other dams not included in the study.

Ethics. The experimental protocol was approved of by the animal ethics committee before the initiation of the study. 

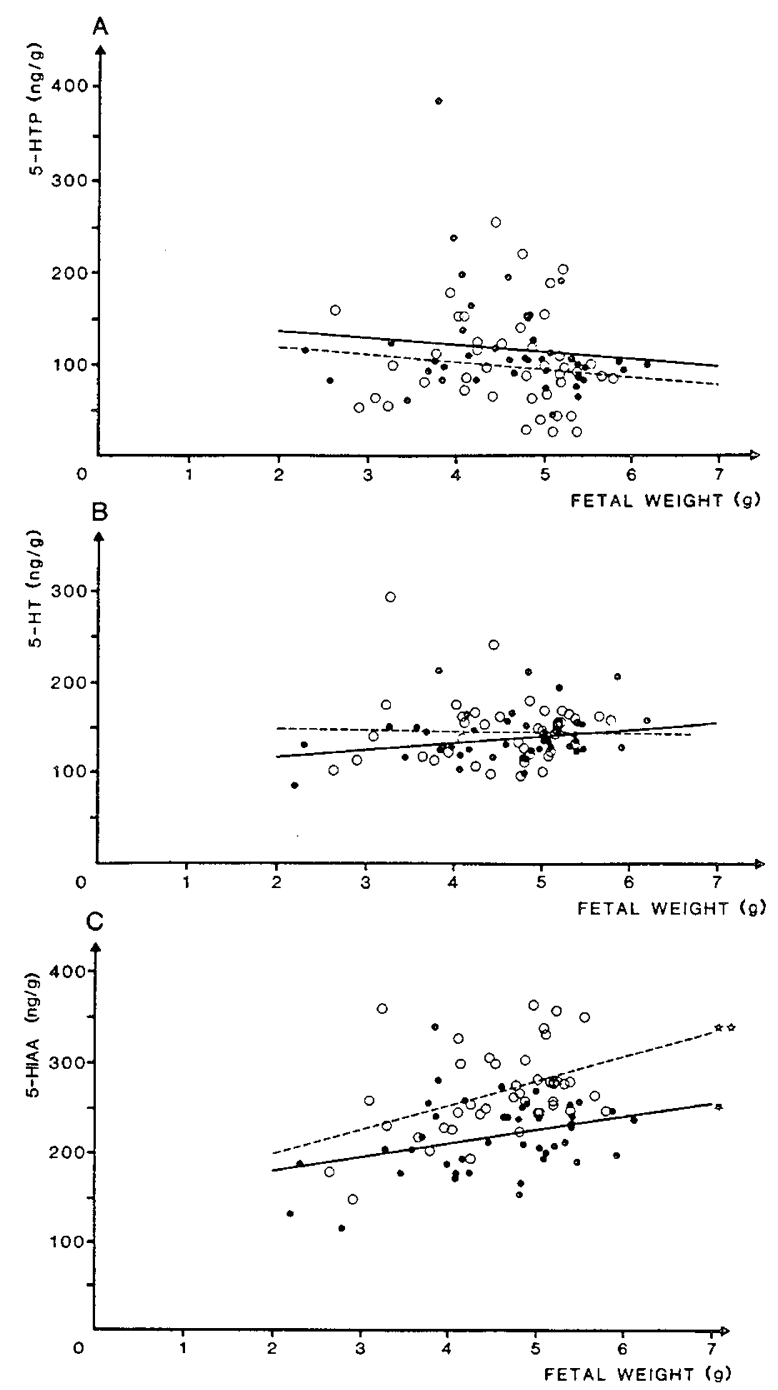

Fig. 4. Concentrations $(\mathrm{ng} / \mathrm{g})$ of serotonin precursor 5-HTP $(A)$, transmitter 5-HT $(B)$, and metabolite 5 -HIAA $(C)$ in brainstem. $A$, Normoxia: $y=130.8-5.8 x$; hypoxia: $y=154.3-8.0 x . B$, Normoxia: $y=153.1-1.4 x$; hypoxia: $y=103.2+7.9 x$. C, Normoxia: $y=144.9$ $+27.2 x$; hypoxia: $y=149.0+15.3 x$. Lines and symbols are as indicated in Figure 2.

\section{RESULTS}

Dams. The hemodynamic values, blood gases, and plasma CA in the dams are given in Table 1. At basal conditions, all values were in the normal range and there were no significant differences between the groups. At the time of the second sample, the values of the normoxic group were largely unchanged, whereas the hypoxic group exhibited a significantly reduced oxygen availability and a compensatory hyperventilation $\left(\mathrm{PCO}_{2}\right.$ data not shown) leading to an increased $\mathrm{pH}$. Two min after NSD 1015 had reached the dam, a sympathicotonic reaction appeared in terms of increases in MAP and HR. It peaked 3 min later and was most pronounced in the normoxic group. In this group the sympathetic activation disappeared before or within 1 min after the end of infusion (except in one animal), whereas in hypoxic animals it was present $1-15$ min after the end of infusion (MAP) or never disappeared (HR). Thus, at the final sample the hypoxic group had tachycardia, reduced oxygen availability, and increased $\mathrm{pH}$, as at sample 2. Plasma $\mathrm{E}$ increased in parallel in the two groups.

Fetuses. The AGA fetuses from the normoxic and hypoxic groups were similar (weight $5.16 \pm 0.28$ versus $5.23 \pm 0.38 \mathrm{~g}$, mean $\pm \mathrm{SD}, n=22$ in both groups). Organ weights are shown in Figure 2. Forebrain and liver weights were significantly dependent on fetal weight. No such relation was seen for adrenal or brainstem weight in the normoxic group, but could be seen for brainstem weight in the hypoxic group.

The brainstem content of the endogenous transmitters (DA, $\mathrm{NE}$, and 5-HT) as well as their precursors and metabolites is demonstrated in Figures 3 and 4. A reduced DA concentration was seen in growth-retarded fetuses under normoxia. This could not be demonstrated under hypoxic conditions. The content of 5-HIAA was weight-related under both normoxia and hypoxia. Hypoxia, however, reduced 5-HIAA levels mainly in AGA fetuses $(285.0 \pm 40.8$ versus $222.4 \pm 30.5 \mathrm{ng} / \mathrm{g}$, mean $\pm \mathrm{SD}, p<$ $0.001)$.

The content of MA in the forebrain is shown in Figures 5 and 6. Under normoxia, there was an increased concentration of DOPA and a decrease of DOPAC in fetuses with IUGR compared with AGA fetuses (Fig. 5). These changes were not seen under hypoxia, where fetuses with IUGR instead had increased levels of NE. Under normoxia, fetuses with IUGR had lower concentrations of 5-HT and 5-HIAA compared with AGA fetuses (Fig. 6). Under hypoxia, compared with normoxia, the levels of 5-HT $(69.0 \pm 16.4$ versus $100.8 \pm 34.2 \mathrm{ng} / \mathrm{g}, p<0.001)$ and 5 HIAA $(80.6 \pm 14.5$ versus $112.6 \pm 39.9 \mathrm{ng} / \mathrm{g}, p<0.001)$ were reduced in AGA fetuses. Fetuses with IUGR, however, showed a sharp increase of 5-HTP compared to AGA fetuses $(p<0.001$ even when the extremely high value of the smallest fetus was excluded).

CA concentrations in adrenal glands are demonstrated in Figure 7. Under normoxia, fetuses with IUGR had reduced levels of $\mathrm{E}$. This was even more pronounced under hypoxia where also NE levels were reduced. The increase in NE $(82.5 \pm 17.8$ versus $57.9 \pm 20.2 \mathrm{ng} / \mathrm{g}, p<0.001)$ and $\mathrm{E}(251.8 \pm 31.9$ versus 173.5 $\pm 59.6 \mathrm{ng} / \mathrm{g}, p<0.001)$ concentrations seen in AGA fetuses under hypoxia could not be demonstrated in fetuses with IUGR.

\section{DISCUSSION}

Growth-retarded rat fetuses in late pregnancy demonstrated disturbances mainly of forebrain growth (Fig. 2) and forebrain serotonin metabolism (Fig. 6) in this model of asymmetric IUGR, the type that in man dominates in countries where malnutrition is uncommon (25). Experiments were performed the day before term in awake dams with normal hemodynamics and blood gas status under basal conditions (Table 1). Half of the dams were subjected to a mild hypoxia, producing a moderately reduced availability of oxygen in arterial blood (Table 1). Thus, the model illustrates the effect of IUGR per se and that of IUGR with a superimposed, acute hypoxia.

To estimate the effects of IUGR with or without hypoxia on central and peripheral MA metabolism, we measured the endogenous transmitters, their precursors, and some of the metabolites formed. The first and rate-limiting step $(30,31)$ in the synthesis of MA is the hydroxylation of L-tyrosine and L-tryptophan to LDOPA and L-5-HTP by the specific enzymes tyrosine and tryptophan hydroxylase, respectively. The tyrosine and tryptophan hydroxylases are, under normal conditions in the adult, saturated to approximately 75 and $50 \%$, respectively, and are highly sensitive to hypoxia because they use molecular oxygen as cosubstrate (32). The next step, the decarboxylation of L-DOPA to DA and 5-HTP to 5-HT, is catalyzed by aromatic L-amino acid decarboxylase, which can be inhibited by NSD 1015. The activity of the rate-limiting enzymes, i.e. the synthetic activity, can thus be estimated by administering NSD 1015, inasmuch as L-DOPA and 5-HTP accumulate intraneuronally and linearly for the first $30 \mathrm{~min}$ and are not appreciably metabolized or transported away (33). However, the concentrations of the transmitters themselves (DA, NE, and 5-HT) are not changed by the administration of NSD 1015 (33) and, therefore, the NSD 1015 method represents a relevant technique not only for estimating synthesis activity but also for measuring endogenous transmitter levels in brain 

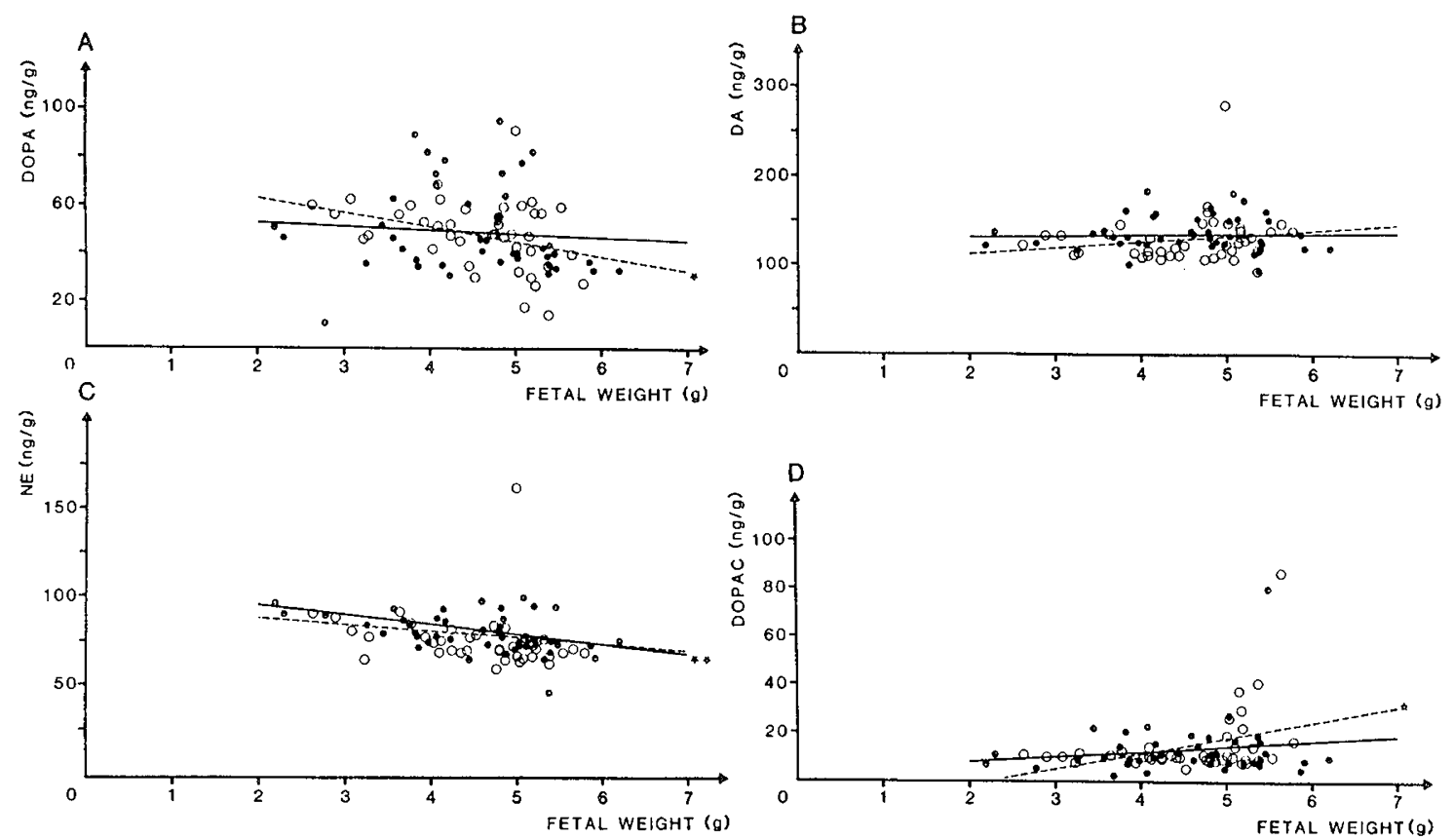

Fig. 5. Concentrations (ng/g) of CA precursor DOPA $(A)$, transmitters DA $(B)$ and NE $(C)$, and metabolite DOPAC $(D)$ in forebrain. $A$, Normoxia: $y=76.9-6.3 x$; hypoxia: $y=56.5-1.5 x . B$, Normoxia: $y=99.4+6.9 x$; hypoxia: $y=130.6+1.2 x$. $C$, Normoxia: $y=93.5-3.6 x$; hypoxia: $y=103.3-5.2 x . D$, Normoxia: $y=-14.2+6.4 x$; hypoxia: $y=3.9+2.0 x$. Lines and symbols are as indicated in Figure 2 .

tissue. The passage of NSD 1015 over the placenta has not been measured. However, the substance probably readily passes the placenta inasmuch as the blood-brain barrier is passed without difficulty (33). Furthermore, the values of 5-HTP and DOPA that we measured usually were much higher than levels in the adult without administration of NSD 1015 (33) and were similar to those seen in neonatal rats after NSD 1015 administration (34).

In normoxic animals, NSD 1015 caused a transient increase of both MAP and HR, whereas hypoxic dams exhibited this pattern for MAP but had a permanently increased HR. In both experimental groups, plasma $\mathrm{E}$ increased. Those were increases compared with both basal levels and dams treated similarly but not exposed to NSD 1015. A control series was carried out in which three dams were exposed to normoxia and three to hypoxia. No NSD 1015 was infused. The hemodynamic and blood gas values were similar to those seen in the experimental dams. There were, however, no such increases in HR or plasma $E$ at sample 3 as in the NSD 1015-infused dams. These changes are thus explained by a sympathicomimetic action of NSD 1015, probably of central origin (Bengt Persson, personal communication). The rise in $\mathrm{E}$ in normoxic dams could have affected fetal supply of oxygen and nutrients through a decreased placental perfusion. Infusion of $\mathrm{E}$ in sheep, however, does not influence fetal MAP, blood gas status, or oxygen consumption (35). In the hypoxic group, the rise in MAP lasted longer than in the normoxic group. Inasmuch as an increase in MAP probably reflects peripheral vasoconstriction, including preplacental vessels, this would add to the decreased supply of the fetuses of this group.

The weight of adrenal glands was not affected in growthretarded fetuses (Fig. 2). However, during normoxic conditions, the $\mathrm{E}$ concentration was reduced in proportion to body weight (Fig. 7). This could indicate an increased release in growthretarded fetuses (36), especially if synthesis rate is increased as in the growth-retarded rat neonate (37). Under hypoxia, AGA fetuses increased the tissue content of $\mathrm{NE}$ and $\mathrm{E}$, probably as a result of the rate of synthesis increasing more than that of release (37). This response was not present in fetuses with IUGR in this study or in the rate neonate with IUGR in which synthesis and release were measured (37). Thus, these findings indicate a reduced capacity of the sympathoadrenal system in fetuses with IUGR to respond to hypoxic stress.

Brainstem weight was not reduced in normoxic fetuses with IUGR, whereas a reduction was seen in hypoxic ones (Fig. 2). This difference probably reflects inexact dissection, inasmuch as the caudal end of the brainstem specimen was not precisely defined but was taken as the level of decapitation. Data on brainstem weight must therefore be interpreted with caution. The caudal end of the brainstem specimen was, however, always below the level of the cervical flexure, i.e. below the cell bodies of the MA neurons (38). Thus, if anything, the MA levels in fetuses with IUGR under hypoxia could be too high because less of the spinal cord (low concentrations) was included. MA turnover was only slightly changed in fetuses with IUGR, i.e. moderately reduced DA concentrations under normoxia and 5-HIAA concentrations under normoxia and hypoxia (Figs. 3 and 4). Under hypoxic conditions, there was a reduced amount of 5HIAA in AGA fetuses. The hypoxia-induced changes in 5-HIAA are probably explained by a reduced activity of monoamine oxidase, inasmuch as this enzyme requires molecular oxygen for the conversion of 5-HT to 5-HIAA (39).

A reduction of forebrain weight was found in fetuses with IUGR compared to AGA fetuses (Fig. 2). Concentrations of CA showed slight changes with dubious biologic significance. However, 5-HT turnover was influenced in fetuses with IUGR (Fig. 6 ). The fact that 5-HT was mostly affected might be explained by a more mature synthetic system as compared to DA and NE (38). Under normoxia, reduced degradation and reduced transmitter concentration were seen in fetuses with IUGR. This could be due to a reduced supply of tryptophan, signs of which have been found in the human (40), or a decreased activity of the highly hypoxia-sensitive, rate-limiting enzyme (tryptophan-hydroxylase) (23) caused by a slight hypoxia in fetuses with IUGR (21). In AGA fetuses under hypoxia, the concentrations of 5-HT and 5-HIAA were both reduced compared to those under normoxia, whereas, surprisingly, fetuses with IUGR demonstrated a marked increase in synthetic activity compared to AGA fetuses. The background to this paradoxical reaction might be related to changes in the activity of excitatory amino acid transmitters (41, 42) or to increased levels of maternal or fetal glucocorticoids (14). In light of the present findings of altered 5-HT turnover in 

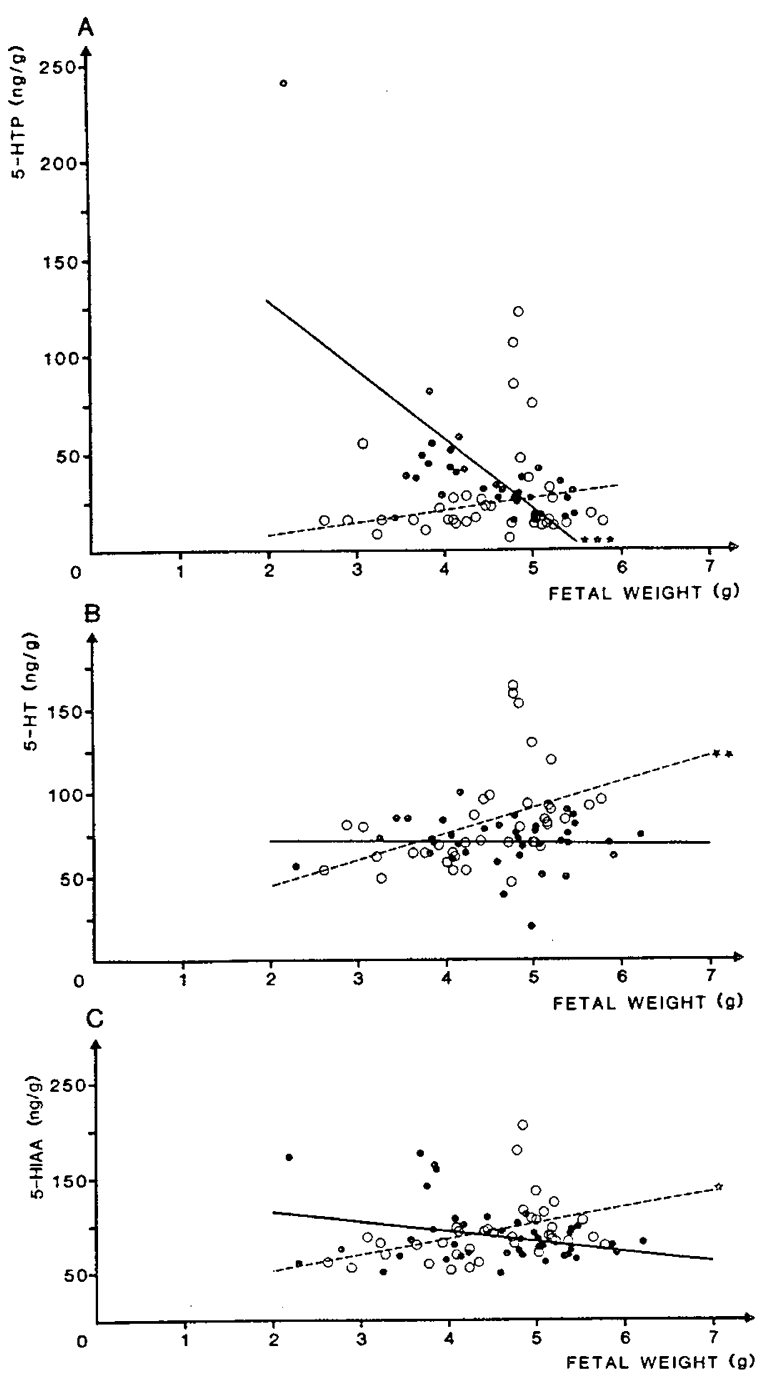

Fig. 6. Concentrations (ng/g) of serotonin precursor 5-HTP $(A)$, transmitter 5-HT $(B)$, and metabolite 5-HIAA $(C)$ in forebrain. $A$, Normoxia: $y=8.8+4.3 x$; hypoxia: $y=200.0-35.7 x$. $B$, Normoxia: $y$ $=12.9+15.7 x$; hypoxia: $y=73.1-0.7 x$. $C$, Normoxia: $y=21.4+$ $16.1 x$, hypoxia: $y=135.2-10.3 x$. Lines and symbols are as indicated in Figure 2.

IUGR, earlier contradictory reports might be explained in terms of different levels of stress to the fetus with IUGR. A low level of stress (IUGR of late onset) might induce a decreased 5-HT activity (43), and aggravated stress (IUGR of early onset) could produce increased activity (44). The latter might induce a precocious development of evoked potentials (12) due to an earlier switch from proliferation to differentiation (14).

From this study it seems that the phenomenon of brain-sparing in IUGR of late onset shows a selectivity in the rat; caudal brain regions that are developed early are spared more than rostral, later-developing regions in terms of growth and 5-HT turnover. The same regional difference has been shown for $\mathrm{Na}^{+} / \mathrm{K}^{+}$-ATPase activity in the rat neonate with IUGR (45). This could be the result of later-developing parts being more sensitive to adverse influences or an active process favoring the most important parts where centers for autonomic control are located. Because 5-HT has been shown to have trophic effects on brain development and metabolism $(14,46)$, the present findings of a reduced 5-HT activity under basal conditions could, if extrapolated to the human situation, be part of the pathophysiology of retarded forebrain development, motor function in fetuses $(7,8,40)$, and evoked potentials in neonates $(10)$.

An induced, excessive release of 5-HT in the adult rat damages
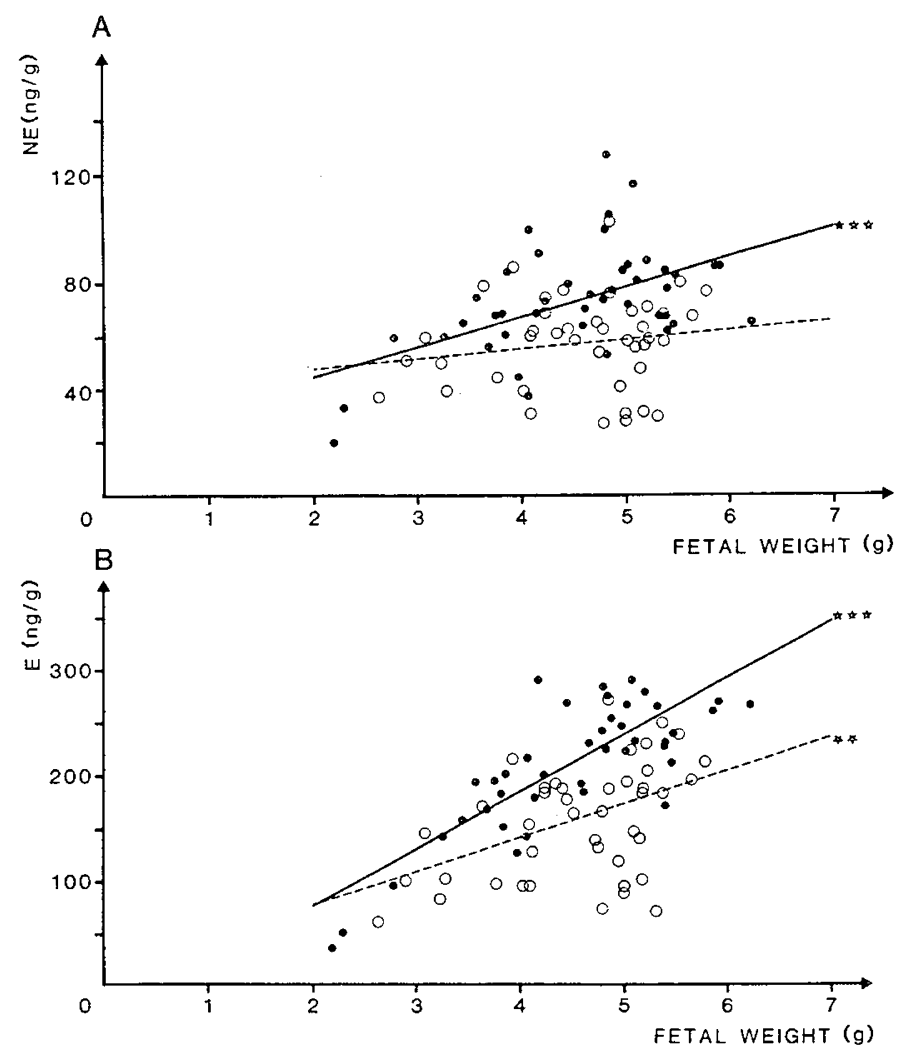

Fig. 7. Concentrations (ng/g) of NE $(A)$ and $\mathrm{E}(B)$ in adrenals. $A$, Normoxia: $y=41.6+3.6 x$; hypoxia: $y=22.2+11.4 x$. $B$, Normoxia: $y$ $=10.4+32.4 x$; hypoxia: $y=-34.2+54.5 x$. Lines and symbols are as indicated in Figure 2.

serotonergic neurons, probably through the formation of oxygen free radicals via the endogenous toxin 5,6-dihydroxytryptamine $(47,48) .5-\mathrm{HT}_{2}$-receptor antagonists protect against cerebral ischemia (19), and a reduced synthesis rate in the neonate prolongs survival under anoxia (18). Thus, an increased synthesis (as seen here in forebrain of fetuses with IUGR under hypoxia) could be adverse and possibly lead to brain damage.

In conclusion, we have demonstrated that rat fetuses with IUGR in late gestation exhibit disturbances of central nervous MA metabolism, mainly that of 5-HT in forebrain. Most striking is a paradoxical reaction in terms of an increased 5-HT synthesis during acute hypoxia. The magnitude of these changes is dependent on the degree of growth retardation. Thus, also fetuses and neonates with a minor degree of growth retardation may have an abnormal central nervous MA metabolism and an increased sensitivity to perinatal stress.

\section{REFERENCES}

1. Calame A, Fawer CL, Claeys V, Arrazola L, Ducret S, Jaunin L 1986 Neurodevelopmental outcome and school performance of very-low-birthweight infants at 8 years of age. Eur J Pediatr 145:461-466

2. Walther FJ 1988 Growth and development of term disproportionate small-forgestational age infants at the age of 7 years. Early Hum Dev 18:1-11

3. Hagberg G, Hagberg B, Olow I 1976 The changing panorama of cerebral palsy in Sweden 1954-1970. III. The importance of foetal deprivation of supply. Acta Paediatr Scand 65:403-408

4. Blair E, Stanley F 1990 Intrauterine growth and spastic cerebral palsy: I Association with birth weight for gestational age. Am J Obstet Gynecol 162:229-237

5. Allen MC 1984 Developmental outcome and follow-up of the small for gestational age infant. Semin Perinatol 8:123-156

6. Thordstein M, Kjellmer I 1988 Cerebral tolerance of hypoxia in growthretarded and appropriately grown newborn guinea pigs. Pediatr Res 24: 633-638

7. Bekedam DJ, Visser GHA, de Vries JJ, Prechtl HFR 1985 Motor behaviour in the growth retarded fetus. Early Hum Dev 12:155-165 
8. van Vliet MAT, Martin Jr CB, Nijhuis JG, Prechl HFR 1985 Behavioural states in growth-retarded human fetuses. Early Hum Dev 12:183-197

9. Wladimiroff J, van Bel F 1987 Fetal and neonatal cerebral blood flow. Semin Perinatol 1:335-346

10. Hrbek A, Iversen K, Olsson T 1982 Evaluation of cerebral function in newborn infants with fetal growth retardation. In: Courjon J, Mauguiere F, Revol M (eds) Clinical Applications of Evoked Potentials in Neurology. Raven Press, New York, pp 89-95

11. Carter AM, Gu W 1988 Cerebral blood flow and fetal oxygenation in the growth retarded guinea pig fetus. In: Jones CT (ed) Fetal and Neonatal Development. Perinatology Press, Ithaca, NY, pp 86-89

12. Cook CJ, Gluckman PD, Williams C, Bennet L 1988 Precocial neural function in the growth-retarded fetal lamb. Pediatr Res 24:600-604

13. Chanez C, Priam M, Flexor MA, Hamon M, Bourgoin S, Kordon C, Minkowski A 1981 Long lasting effects of intrauterine growth retardation on 5HT metabolism in the brain of developing rats. Brain Res 207:397-408

14. Lauder JM, Krebs H 1976 Effects of $p$-chlorophenylalanine on time of neural origin during embryogenesis in the rat. Brain Res 107:638-644

15. Dow-Edwards DL, Freed LA, Milhorat TH 1988 Stimulation of brain metabolism by perinatal cocaine exposure. Dev Brain Res 42:137-141

16. Shaywitz BA, Cohen DJ, Bowers MB 1977 CSF monoamine metabolites in children with minimal brain dysfunction: evidence for alteration of brain dopamine. Pediatrics 90:67-71

17. Hedner T, Lundborg P, Engel $\mathbf{J} 1979$ Brain biochemical and behavioral changes in 4 weeks old rats after neonatal oxygen deprivation. Pharmacol Biochem Behav 10:647-650

18. Hedner T 1978 Central monoamine metabolism and neonatal oxygen deprivation. Acta Physiol Scand [Suppl] 460:1-34

19. Fujikura H, Kato H, Nakano S, Kogure K 1989 A serotonin $S_{2}$ antagonist naftidrofuryl, exhibited a protective effect on ischemic neuronal damage in the gerbil. Brain Res 494:387-390

20. Lindvall O, Auer RN, Siesjö BK 1986 Selective lesions of mesostriatal dopamine neurons ameliorate hypoglycemic damage in the caudate-putamen. Exp Brain Res 63:382-386

21. Soothill PW, Nicolaides KH, Campbell S 1987 Prenatal asphyxia, hyperlacticaemia and erythroblastosis in growth retarded fetuses. Br Med J 294: $1051-1053$

22. Jansson T, Persson E 1990 Placental transfer of glucose and amino acids in intrauterine growth retardation: studies with substrate analogs in the awake guinea pig. Pediatr Res 28:203-208

23. Davis JN, Carlsson A, MacMillan V, Siesjö BK 1973 Brain tryptophan hydroxylation: dependence on arterial oxygen tension. Science 182:72-74

24. Tagliamonte A, Biggio G, Vargin L, Gessa GL 1973 Free tryptophan in serum controls brain tryptophan level and serotonin synthesis. Life Sci 12:277-287

25. Chiswick ML 1985 Intrauterine growth retardation. Br Med J 291:845-848

26. Felice LJ, Felice JD, Kissinger PT 1978 Determination of catecholamines in rat brain parts by reverse-phase ion-pair liquid chromatography. J Neurochem 31:1461-1465

27. Magnusson O, Nilsson LB, Westerlund D 1980 Simultaneous determination of dopamine, dopac and homovanillic acid. Direct injection of supernatants from brain homogenates in a liquid-chromatography-electrochemical detection system. J Chromatogr 221:237-247

28. Shum A, Sole MJ, van Loon GR 1982 Simultaneous measurements of 5hydroxytryptophan and L-dihydroxyphenylalanine by high-performance liquid chromatography with electrochemical detection. Measurement of sero- tonin and catecholamine turnover in discrete brain regions. $\mathbf{J}$ Chromatogr 228:123-130

29. Hjemdahl P, Daleskog M, Kahan T 1979 Determination of plasma catecholamine by high performance liquid chromatography with electrochemical detection. Comparison with a radioenzymatic method. Life Sci 25:131-138

30. Levitt M, Spector S, Sjoerdsma A, Udenfriend S 1965 Elucidation of the ratelimiting step in norepinephrine biosynthesis in the perfused guinea pig heart. J Pharmacol Exp Ther 148:1-8

31. Udenfriend S, Titus E, Weissbach H, Peterson RE 1956 Biogenesis and metabolism of 5-hydroxyindole compounds. J Biol Chem 219:335-344

32. Costa E, Neff NH 1970 Estimation of turnover rates to study the metabolic regulation of the steady-state level of neuronal monoamines. In: Handbook of Neurochemistry. Plenum Press, New York, pp 45-90

33. Carlsson A, Davies JN, Kehr W, Lindqvist M, Atack CV 1972 Simultaneous measurements of tyrosine and tryptophan hydroxylase activities in brain in vivo using an inhibitor of the aromatic amino acid decarboxylase. Naunyn Schmiedebergs Arch Pharmacol 275:153-168

34. Hedner T, Lundborg P 1980 Serotonin metabolism in neonatal rat brain during asphyxia and recovery. Acta Physiol Scand 109:163-168

35. Gu W, Jones CT 1986 The effect of elevation of maternal plasma catecholamine on the fetus and placenta of the pregnant sheep. J Dev Physiol 8: $173-186$

36. Jelinek J, Jensen A 1988 Distribution of catecholamines in central and peripheral organs of the fetal guinea pig during normoxaemia, hypoxaemia and asphyxia. In: Künzel W, Jensen A (eds) The Endocrine Control of the Fetus. Springer-Verlag, Berlin, pp 157-170

37. Shaul PW, Cha C-J M, Oh W 1989 Neonatal sympathoadrenal response to acute hypoxia: impairment after experimental intrauterine growth retardation. Pediatr Res 25:466-472

38. Seiger $\AA$, Olson L 1973 Late prenatal ontogeny of central monoamine neurons in the rat: fluroscence histochemical observations. Z Anat Entwicklungsgesch 140:281-318

39. Davis J, Carlsson A 1973 The effect of hypoxia on monoamine synthesis, levels and metabolism in rat brain. $J$ Neurochem 21:783-790

40. Romanini C, Valensise H, Ciotti G, Arduini D, Giorgi P 1989 Tryptophan availability and fetal behavioural states. Fetal Ther 4:68-72

41. Smith JE, Lane JD, Shea PA, McBride WJ 1977 Neurochemical changes following the administration of precursors of biogenic amines. Life Sci 21:301-306

42. McCall RB, Aghajanian GK 1979 Serotonergic facilitation of facial motoneuron excitation. Brain Res 169:11-27

43. Chrzanowska B, Wankowicz B, Prokopczyk 1984 Serotonin concentration in the rat fetal brain in experimental intrauterine growth retardation. Probl Med Wieku Rozwoj 13:193-197

44. Manjarréz G, Chagoya G, Hernańdez J 1988 Perinatal brain serotonin metabolism in rats malnourished in utero. Biol Neonate 54:232-240

45. Chanez C, Flexor M-A, Hamon M 1985 Long lasting effects of intrauterine growth retardation on basal and 5-HT-stimulated $\mathrm{Na}^{+}, \mathrm{K}^{+}$-ATPase in the brain of developing rats. Neurochem Int 7:319-329

46. Hernandez-Rodriguez J, Chagoya G 1986 Brain serotonin synthesis and $\mathrm{Na}^{+}, \mathrm{K}^{+}$-ATPase activity are increased postnatally after prenatal administration of L-tryptophan. Dev Brain Res 25:221-226

47. Commins DL, Axt KJ, Vosmer G, Seiden LS 1987 5,6-Dihydroxytryptamine a serotonergic neurotoxin, is formed endogenously in rat brain. Brain Res 403:7-14

48. De Vito MJ, Wagner GC 1989 Functional consequences following metamphetamine-induced neuronal damage. Psychopharmacology 97:432-435 